\title{
Tropical cyclone-induced extreme winds in climate datasets: East coast of Australia
}

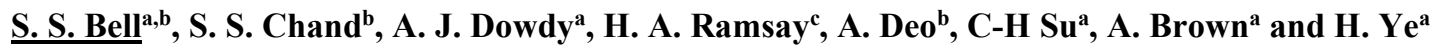 \\ ${ }^{a}$ Bureau of Meteorology, Docklands, Australia, ${ }^{b}$ School of Engineering, IT and Physical Sciences, \\ Federation University Australia ${ }^{c}$ CSIRO Oceans and Atmosphere, Aspendale, Australia \\ Email: samuel.bell@bom.gov.au
}

\begin{abstract}
Extreme wind speeds, which are typically induced by tropical cyclones (TCs) in coastal regions of tropical Australia, are an important hazard to consider in the context of climate change. Here, a range of climate datasets based on direct observations, reanalyses and regional climate model simulations are used to examine trends in TC-related extreme winds over coastal Eastern Australia. Wind gust speed estimates from best-track data and automatic weather station (AWS) observations are used to calibrate reanalysis wind gusts from the Bureau of Meteorology (BoM) Atmospheric high-resolution Regional Reanalysis for Australia (BARRA) and from the global ERA5 reanalysis. Together, these different datasets provide complementary lines of evidence in relation to historical changes in extreme wind gust speeds.
\end{abstract}

Differences between the occurrence frequency of TC-related wind gusts reaching Category 4/5 on the Australian TC intensity scale and the return periods of TC-related wind gusts over three decades (1990-2019) are presented. Lognormal and Weibull curves are fitted to the extreme value wind speeds and used to provide estimates of associated return periods. Results indicate that the East coast has likely experienced a slightly increased frequency of extreme wind gusts from TCs over the more recent time period (2005-2019), noting considerable uncertainties around these extremes given the limitations of the available data, including that of rapidly evolving observational practices and short time period.

Projection results from climate models provide can provide a more homogenous evaluation of the impacts of climate change over a longer time period than is currently available, despite having their own limitations such as model biases and inaccurate representation of certain climate processes. The same experimental methods applied to the observational datasets, are here applied to future projections based on several regional climate model (RCM) simulations under high emission scenarios: NSW and ACT Regional Climate Modelling (NARCliM), CSIRO Conformal Cubic Atmospheric Model (CCAM) and BoM's Atmospheric Regional Projections for Australia (BARPA). NARCliM results are downscaled from a selection CMIP3 models and use a mean wind speed rather than a gust, while CCAM and BARPA results are downscaled from a selection of CMIP5 models. Results from these projections on extreme wind speeds are generally inconclusive for climate trends on the East coast but indicated that an increase in intensity would be more likely than a decrease in a warmer world.

Small sample size and considerable interannual variability in landfalling severe TCs means that there are considerable uncertainties around long-term observed trends in their occurrence. However, a small increase in the observed occurrence frequency of severe TCs for the East coast is noted here based on observations, such that an increase in the more damaging wind gust speeds associated with severe TCs (i.e., rare events with higher return period values) is a plausible outcome for the future climate of Eastern Australia. For example, the return period projections from the regional climate models generally suggest an increase is more likely than a decrease for the most extreme wind gust speeds. We note that whether a change in long-term return periods of wind gusts or a change in the frequency of TC landfalls of any intensity is more important is likely specific to the region or application being considered. Although there are considerable uncertainties around this topic of extreme wind gusts and TCs in a changing climate, our findings are intended to help contribute to the range of guidance available in relation to managing climate risk in Eastern Australia.

Keywords: Reanalysis, climate model, regional downscaling, tropical cyclones, wind speed return periods 


\section{INTRODUCTION}

Extreme weather events, such as those associated with tropical cyclone (TC) induced wind speeds can have large impacts on coastal communities and infrastructure situated in tropical Australia. A clearer understanding of these extreme events could be important for disaster risk management and planning, particularly in the context of anthropogenic-induced climate change. For example, there is medium-to-high confidence (e.g., Mastrandrea et al. 2010) of increased globally-averaged TC intensity with projected future warming (Knutson et al. 2020). Additionally, recent work based on observations has shown that the proportion of major TC subdaily intensities (i.e., Australian Category 4/5, Table 1) around the globe have fractionally increased over the past 40 years at a statistically significant rate (Kossin et al. 2020).

In Australia, the topic of TCs and extreme wind gust speeds has received widespread attention, including in relation to building codes and Australian structural design standards. Individual case studies have explored this issue in depth (e.g., Mason and Haynes 2010), including comparison of wind gusts from several different sources such as those from weather stations and satellite-derived information. Here we are not attempting to rewrite the standard but look to employ similar established techniques that are used in this field to help in our understanding of climate related trends for wind speed extremes The use of multiple data sources for extreme wind speed analyses can help increase confidence in results, particularly given the degree of uncertainty around the more extreme values and how they might potentially be changing in a warming world. In particular, rather than just relying on a single dataset and method, a consideration to multiple lines of evidence can help lead to a more comprehensive understanding of potential long-term changes; an approach that is followed here. Wang et al. (2013) found that structures along the north-east coast of Australia may be already subject to higher gust speeds than the current design standard permits, with projected changes in extreme wind gust speeds being sensitive to TC frequency and intensity change. These findings for north-east Australia are consistent with a recent study by Holmes (2020), who related increasing extreme wind gust speeds for this region with an increasing frequency of Category 4/5 TCs, and suggested a "climate-change multiplier" be applied to the standard (i.e., AS NZS 1170.2).

The simulation of extreme weather events such as peak wind gust speeds from TCs in reanalysis products and climate models poses many challenges, and typically, models are not fine enough to resolve the absolute wind gust speeds of the most intense (Category 4-5) TC events (e.g., Knutson et al. 2020). However, it is expected that improvements in simulating extremes will occur as our understanding of convective and mesoscale processes improves and as more and more finer resolution models are employed. Here we examine how well the BARRA ( $\mathrm{Su}$ et a. 2019) and ERA5 (Hersbach et al. 2020) reanalysis datasets represent TC-induced extreme wind gusts when compared with direct observations [including best-track estimates of TC wind speeds (Dvorak 1973; Velden et al. 2006; Velden et al. 2012) and BoM weather station records]. Reanalysis wind gust data are calibrated to the observational data. We seek to identify any changes in the occurrence frequency of the most damaging Category 4 and above TCs [i.e., TCs with wind gusts $\geq 225 \mathrm{~km} \mathrm{~h}-1\left(\sim 62 \mathrm{~m} \mathrm{~s}^{-}\right.$ ${ }^{1}$ ), for 3 -second wind gust speed] and in the trends of the associated return periods. These methods are then applied to simulations of extreme wind speeds for the projected future climate based on three different regional climate modelling approaches including NARCliM (Evans and Ji 2012a,b), CCAM (McGregor and Dix 2008), and BARPA (Su et al. 2021), to complement our results over the historical period.

\section{METHODS}

\subsection{Data}

Detailed descriptions of the data used can be found in Bell et al. (2021) available online at (http://www.bom.gov.au/research/publications/researchreports/BRR-056.pdf). 


\subsection{TC-related wind gusts}

Here, measures of wind gust maxima are confined to a region that extends $\sim 200 \mathrm{~km}$ from the Eastern Australian tropical coastline (Figure 1). We consider daily-maximum wind gusts to be "TC-related" if on that day the centre of a TC is either positioned inside the region or within $\sim 220 \mathrm{~km}\left(2^{\circ}\right.$ lat) of the region's edge. That is, an additional $\sim 220 \mathrm{~km}$ extending from these region bounds defines the "TC-influencing region"; where a TC must enter at some point in its lifetime; that also defines the boundary for weather station data. Once a TC enters this region, it is considered "influential" over every date of its lifetime that it is within $8^{\circ}$ of the edge of the region. A TC is also considered influential for an additional day after it was determined to dissipate. This is to account for discrepancies in TC location and time between observed and reanalysis data; and to also account for any limitations (e.g., premature terminations) in the TC tracking algorithm used in the climate models. This definition does not remove days where extra-tropical transition occurs in the BoM TC dataset.

Here we define two measures of TC-related wind gust maxima:

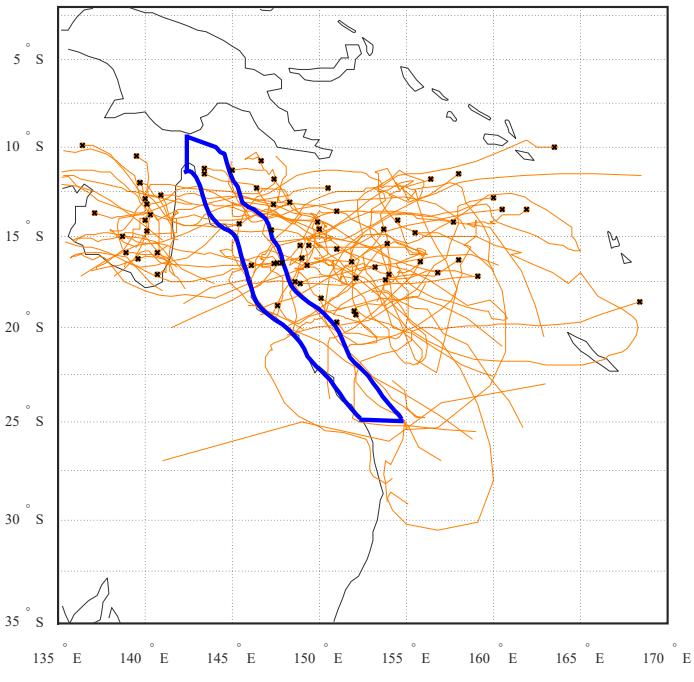

Figure 1. Wind speed hazard study region (blue) and TC tracks (orange).

- TC-max: The maximum TC-related region-daily-maximum wind gust (0:00 to 23:00 UTC) experienced over a TC's lifetime (one value per TC).

- TC day: A selection of region-daily-maximum wind gusts experienced while a TC is present (several values per TC).

\subsection{Calibration of data}

Quantile-quantile (Q-Q) scaling is used to calibrate each reanalysis dataset to the observations. Reanalyses provide wind gust estimates across regions (i.e., grid cells) rather than point locations, which means they cannot be directly compared at coarse resolutions without calibration. Wind gusts measured from two sources act as the "truth": weather stations (AWS) and best track estimates of TC wind gust speeds. Sampling differences between these two observational sources result in very different extreme wind gust distributions over the past 30 years such that gusts rarely exceed $50 \mathrm{~m} \mathrm{~s}^{-1}$ for the station data and reach up to $100 \mathrm{~m} \mathrm{~s}^{-1}$ in the best track data (Figure 2). The RCM data are not calibrated. Thresholds used for the raw BARRA data (Fig. 2b) can give a reasonable estimate for severe category wind speeds in the CCAM and BARPA data, as these datasets share a common resolution $(\sim 12 \mathrm{~km})$. The finer scale resolution of BARPA (BARPA-C) can be considered almost fully resolved, as there are wind gusts up to $100 \mathrm{~m} \mathrm{~s}^{-1}$ (Fig. 2j), similar to the satellite observation dataset (Fig. 2b). The much coarser NARCliM data $(\sim 50 \mathrm{~km})$ shows expectedly lower absolute values of winds, also noting that NARCliM uses a mean wind speed in comparison to the other datasets in which a 3-second wind gust or otherwise instantaneous wind speed is used. These facts generally make the NARCliM results more difficult to compare to the others. The slight bi-modal distribution of the best-track data (Fig. 2b; Lee et al. 2016) appears not to be simulated by any other dataset with exception of CCAM (Fig. 2j) in which it appears to be greatly exaggerated; likely due to a too aggressive convection parameterisation scheme resulting in an underrepresentation of intermediate wind speeds around $55 \mathrm{~m} \mathrm{~s}^{-1}$.

\subsection{Extreme value modelling}

The lognormal and Weibull functions best modelled the tails of our wind gust distributions in comparison to other functions (such as generalised extreme value and Gumbel; not shown) and the parameter estimation method of maximum likelihood was preferred in comparison to other parameter estimation methods (e.g., Lmoments, Hosking 1990). In cases where the lognormal function did not provide a good fit to our data (mostly for cases with tail-heavy distributions) and often resulted in a 25-year return period curve estimate exceeding a theoretical maximum wind gust intensity of $\sim 120 \mathrm{~m} \mathrm{~s}^{-1}$, the Weibull distribution was used instead. 

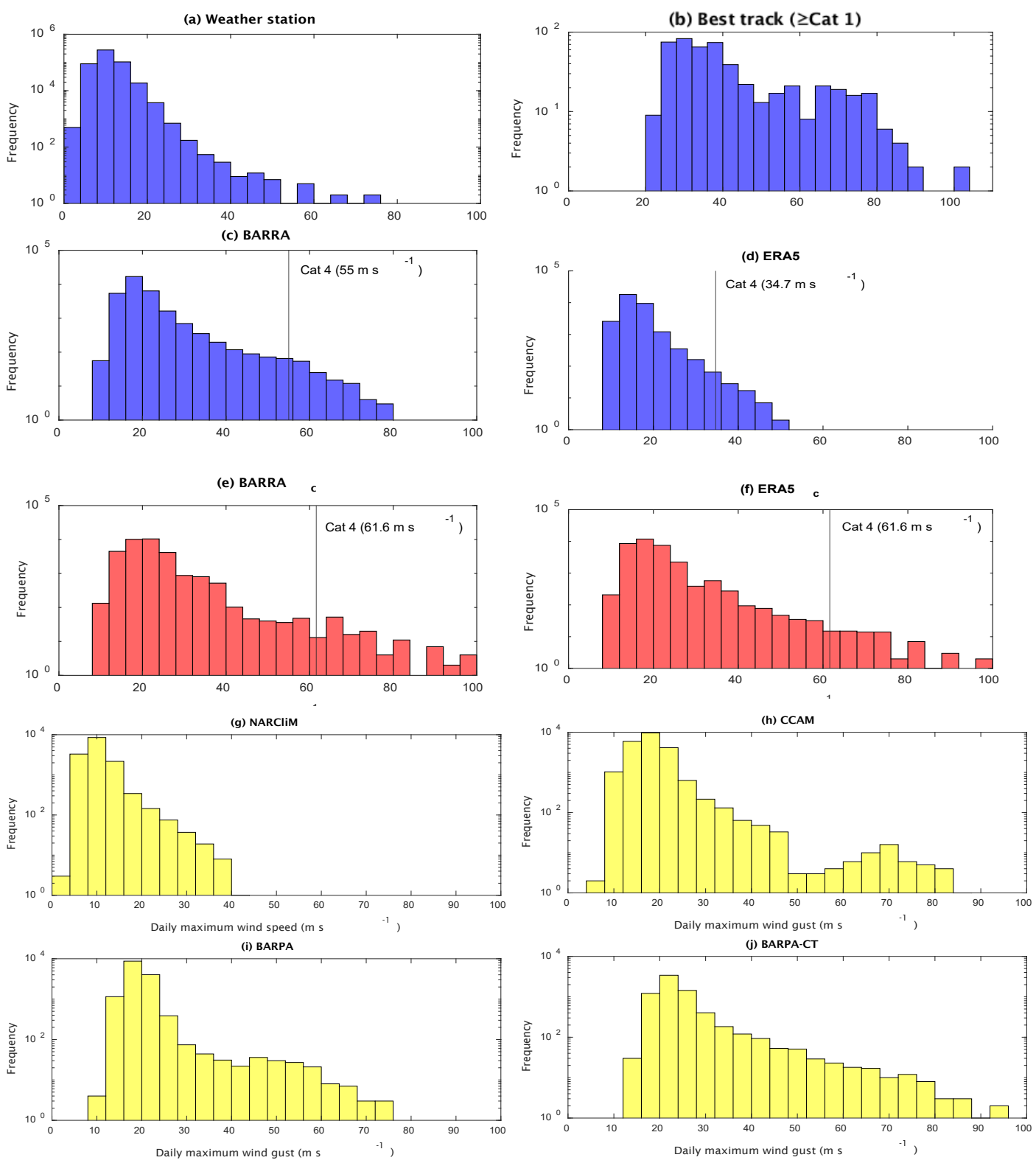

Figure 2. Daily maximum wind gusts frequency distributions (log-scale y-axis) affecting coastal tropical eastern Australia for several datasets. Calibrated reanalysis data are denoted by the subscript c (e-f)., including with calibration applied (e-f). Uncalibrated RCM data are also shown (g-j). A vertical black line denotes the wind gust speed corresponding to a Category 4 (Cat 4) TC in the raw and calibrated reanalysis datasets (c-f).

\section{RESULTS BASED ON OBSERVATION AND REANALYSIS DATA}

Return period curve estimates for two periods (1990-2004 and 2005-2019) are plotted over geometric representations of TC-wind gust maxima (i.e., the strongest wind gust value is expected to occur once over a 15-year period) for the TC-max and TC day representations of wind gust maxima (Figure 3). Return period curves of TC-max wind gusts for the East coast indicate some evidence of stronger wind gusts occurring over the second period (red curves) as these are all displaced upward relative to the earlier period curves (blue), although only the AWS and best-track were significant at the generous $80 \%$ confidence level (the curves shown are the upper and lower estimates of the actual fit). Notably, the TC day curves are calculated from more values in comparison to the TC-max curves, enabling the TC day curves to have a narrower range under the same confidence level. Caution is stressed for interpretation of the AWS curves, as the second period (2005-2019) has a large differential in station availability (not shown) as well suffering from continued under-sampling, resulting in a somewhat unfair comparison. Overall, the observation-only data (AWS and best-track) are indicative of more substantial increases in wind gust extremes as compared to the calibrated reanalysis datasets. These conclusions are further complicated by some sometimes inadequate fitting of extreme value curves over the short time period analysed. 

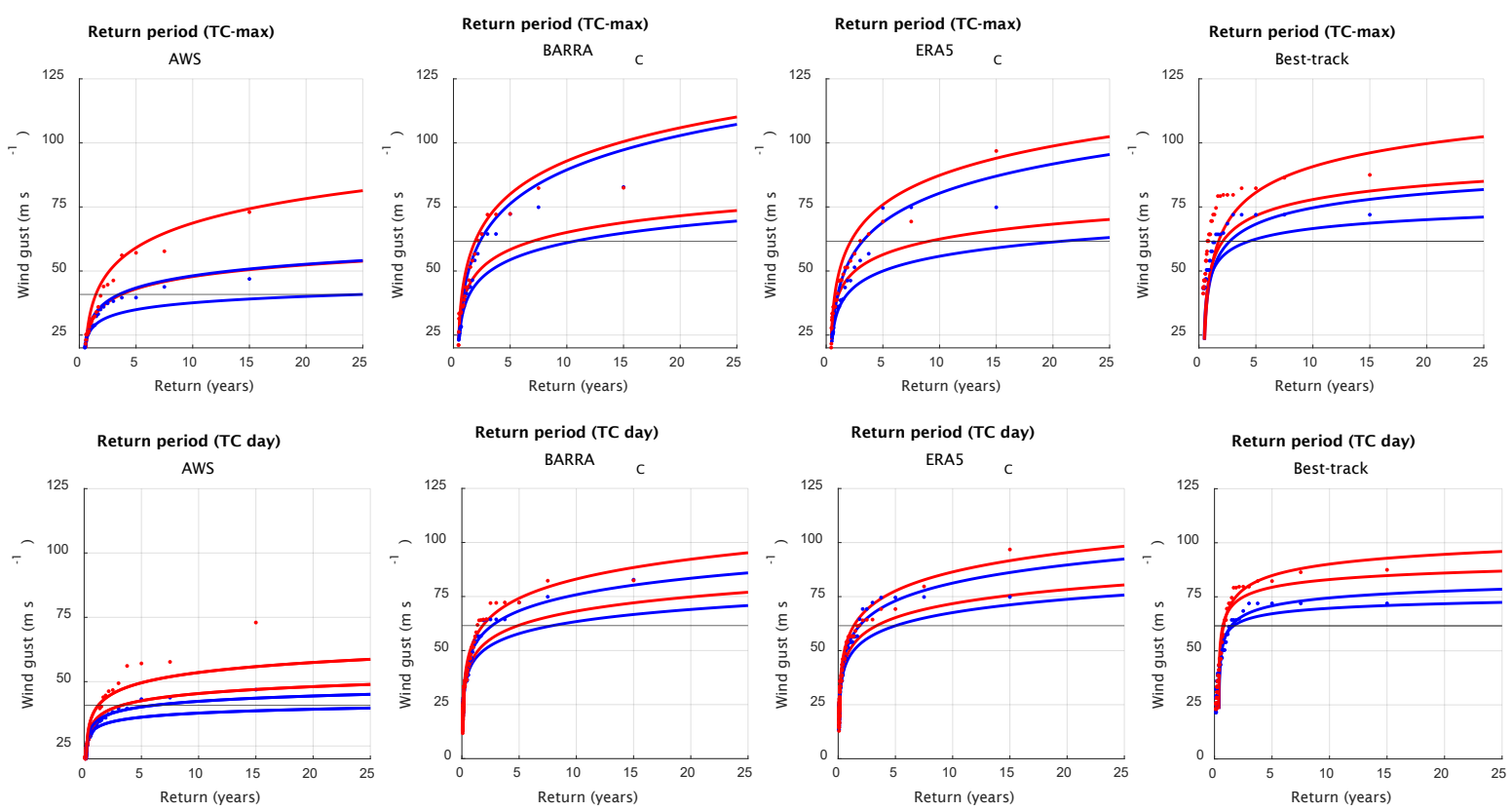

Figure 3. Return period curve estimates of $\mathrm{Au}$ $\sim 80-90 \%$ confidence estimates) and geometric

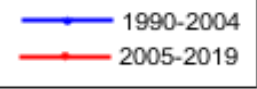

;t wind gust extrema (blue and red lines extrema (blue and red dots). Horizontal black lines indicate a Category 4 or proxy equivalent wind gust.

\section{RESULTS BASED ON CLIMATE MODEL DATA}

The following results are regional downscaled climate model projections based on CMIP3 (NARCliM) and CMIP5 (CCAM and BARPA) models. The A2 emission scenario is applied in the CMIP3 models (IPCC, 2000) while the RCP8.5 emission scenario (van Vuuren et al. 2011) is applied in the CMIP5 models.

Median return period curves are used for the NARCliM and CCAM regional downscaling ensembles (that is the ranked $6^{\text {th }}$ and $7^{\text {th }}$ ensemble curves are averaged to obtain the median curve for NARCliM and the $3^{\text {rd }}$ ranked ensemble curve is used for CCAM) to interpret results. Overall, results (Figure 4) range from no detectable change to a slight upward trend present in the BARPA products between the given sample periods. For the BARPA-C (convection permitting scale) simulation, there are only half as many severe TCs over the second period (RCP8.5), however three of these simulated TCs reached a maximum wind gust speed of greater magnitude (i.e. $>80 \mathrm{~m} \mathrm{~s}^{-1}$ ) than any TCs simulated over the earlier period (not shown). These events enabled a larger upper bound of the second period return curve in the TC-max metric. Similarly, these events supplied enough very intense TC days for both the upper and lower bounds of the second return period to almost exceed the first period in the TC day metric. A similar difference in return period is noted for the default resolution BARPA (BARPA-R), although more very severe (Category 4/5) TCs were identified over this second period in contrast to the BARPA-C results (not shown); albeit the longer 70-year period as compared to the 20-year sample of the convection scale runs (BARPA-C is nested within BARPA-R) is perhaps a stronger indicator of $\mathrm{TC}$ frequency related trends. Different regional climate modelling approaches were unable to support the notion of stronger, more frequent TC-related extreme wind speed events as seen in the BARPA products, and the observations for the region analysed. 

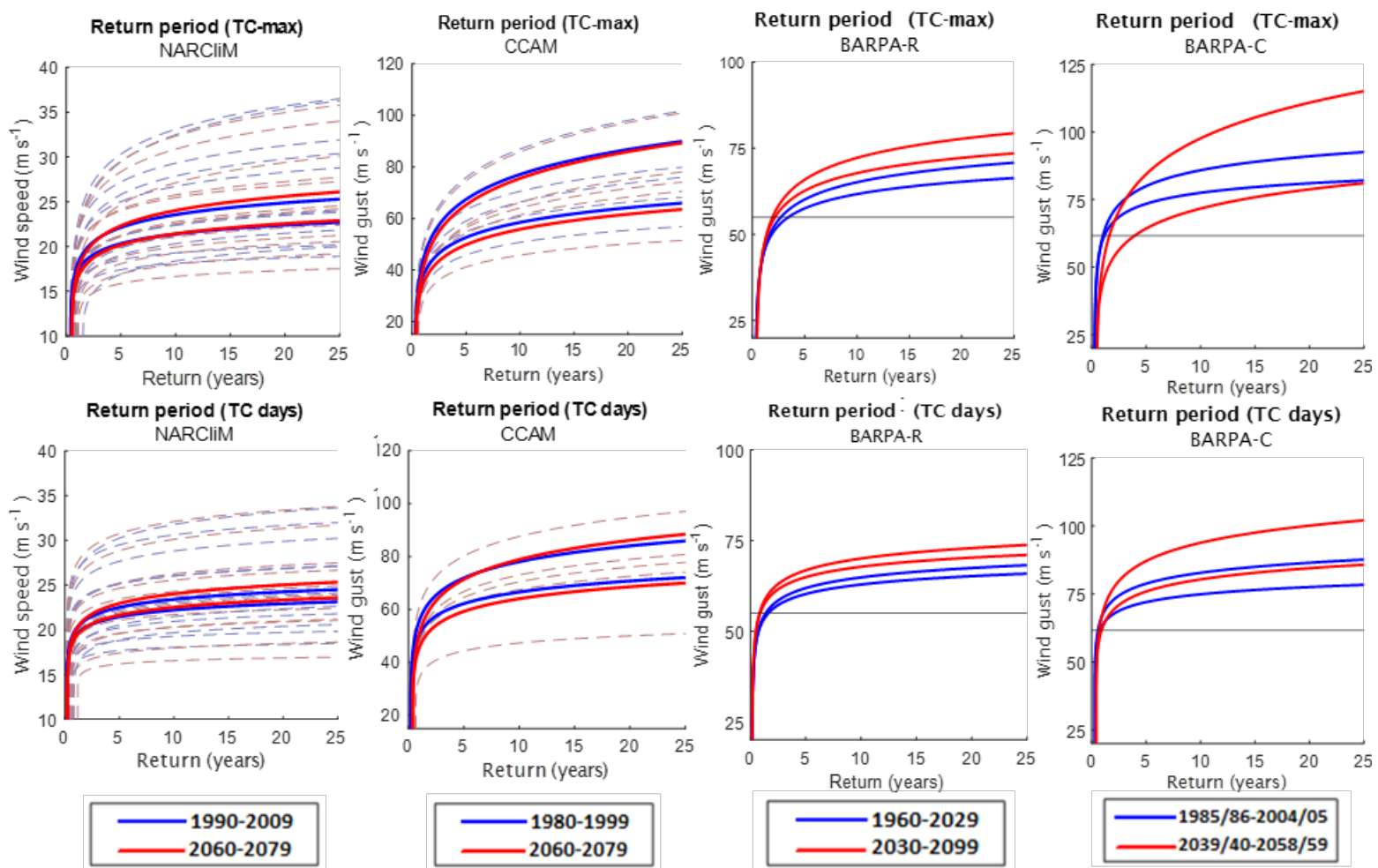

Figure 4. Regional climate model projections of return period curve estimates of Australia tropical East coast wind gust extrema (blue and red lines $\sim 80 \%$ confidence estimates). For NARCliM and CCAM these are the median return curves (individual model curves are represented by dashed lines).

\section{DISCUSSION AND CONCLUSION}

Our findings have provided new lines of evidence in relation to climatological trends of the intensity and frequency of TCs impacting the East coast of Australia, including based on observations and modelling approaches. It is interesting to compare the climatological trends of TCs noted in previous studies with the results presented in this here. Chand et al. (2019) provide statistics on trends in TCs affecting the East Australian coast between the years of 1960-1989 and 1980-2009, allowing for a fair comparison for the East coast region analysed historically here.

Overall, the Chand et al. (2019) study showed TC frequencies have decreased overall for the East coast although this did not translate to a clear change in the frequency of TCs that made landfall. Severe TC frequencies were actually shown to have increased, while noting considerable interannual variability, and the number of severe TCs that made landfall was unchanged. In the context of findings from the present study, such as an increased frequency of historical Category $4 / 5$ wind gust events as well a potential shortening in the return periods of the most extreme TC-max and TC day wind gusts, these results are supportive of other recent observational studies showing TCs impacting on the East coast are likely to have become somewhat more intense and increased in frequency over recent decades.

Projections in this study (from NARCliM, CCAM and BARPA) were somewhat supportive of this trend, with the single ensemble BARPA-related products supporting the historical finding of somewhat more intense on average extreme wind gusts continuing as we approach the 22 nd century.In the context of long-term climate change TC frequency projections (e.g., Bell et al. 2019), the historical results noted here (i.e., Section 3) are consistent with historical trends noted over the past 30 years as no clear change was found for the East coast, as compared to other parts of Australia where a clear decrease was noted. In the context of earlier historical changes noted since the 1870s, Callaghan and Power (2011) found landfalling TCs to have decreased on the East coast, although this finding was attributed to weakening of the Walker circulation and a more El-Niño dominated era rather than global warming in itself. Although there are considerable uncertainties around the topic of TC-induced extreme wind gust speeds in a changing climate, we have collated a broad range of datasets with the aim of providing a comprehensive assessment of available information for examining climate trends in TC-related extreme winds for Eastern Australia.

\section{ACKNOWLEDGMENTS}

This work was supported by funding from the Earth Systems and Climate Change (ESCC) Hub of the Australian Government's National Environmental Science Programme (NESP). Data and expertise provided by Acacia Pepler, Marcus Thatcher, Jason Evans and Andrew Burton toward the study are also acknowledged. 


\section{REFERENCES}

Bell SS, Chand SS, Tory KJ, Dowdy AJ, Turville C, Ye H (2019) Projections of southern hemisphere tropical cyclone track density using CMIP5 models. Climate Dynamics, 52, 6065-6079. https://doi.org/10.1007/s00382-018$\underline{4497-4}$

Bell SS, Chand SS, Dowdy AJ, Ramsay HA, Deo A, SU C-H, Brown A, Ye H (2021) Australian tropical cycloneinduced extreme coastal winds in climate datasets. Bureau Research Report 056, accessible online at http://www.bom.gov.au/research/publications/researchreports/BRR-056.pdf

Callaghan J, Power SB (2011) Variability and decline in the number of severe tropical cyclones making land-fall over eastern Australia since the late nineteenth century. Climate Dynamics, 37, 647-662. https://doi.org/10.1007/s00382-010-0883-2

Chand SS, Dowdy AJ, Ramsay HA, et al. (2019) Review of tropical cyclones in the Australian region: Climatology, variability, predictability, and trends. WIREs Climate Change. 10, e602. https://doi.org/10.1002/wcc.602

Dvorak VF (1973) A Technique For the Analysis and Forecasting of Tropical Cyclone Intensities From Satellite Pictures. NOAA. 5-8.

Evans JP, Ji F (2012a) Choosing GCMs. NARCliM Technical Note 1, 7pp, NARCliM Consortium, Sydney, Australia.

Evans JP, Ji F (2012b) Choosing the RCMs to perform the downscaling. NARCliM Technical Note 2, 8pp, NARCliM Consortium, Sydney, Australia.

Heming JT (2016) Met Office Unified Model Tropical Cyclone Performance Following Major Changes to the Initialization Scheme and a Model Upgrade. Weather and Forecasting, 31, 1433-1449, https://doi.org/10.1175/WAF-D-16-0040.1

Hersbach H, Bell B, Berrisford P et al (2020) The ERA5 Global Reanalysis. Quarterly Journal of the Royal Meteorological Society, 146, 1999-2049, https://doi.org/10.1002/qj.3803.

Holmes, JD (2020) Land-falling tropical cyclones on the queensland coast and implications of climate change for wind loads, Australian Journal of Structural Engineering, 21, 135-142, https://doi.org/10.1080/13287982.2020.1717842

Hosking JRM (1990) L-Moments: Analysis and Estimation of Distributions Using Linear Combinations of Order Statistics. Journal of the Royal Statistical Society, 52, 105-124.

IPCC (2000) Nebojsa Nakicenovic and Rob Swart (Eds.) Cambridge University Press, UK. pp 570 Available from Cambridge University Press, The Edinburgh Building Shaftesbury Road, Cambridge CB2 2RU ENGLAND. Available online at https://www.ipcc.ch/report/emissions-scenarios/?idp=98

Knutson T et al (2020) Tropical Cyclones and Climate Change Assessment: Part II: Projected Response to Anthropogenic Warming. Bulletin of the American Meteorological Society, 101, E303-E322, https://doi.org/10.1175/BAMS-D-18-0194.1.

Kossin JP, Knapp KR, Olander TL, Velden CS (2020) Global increase in major tropical cyclone exceedance probability over the past four decades. Proceedings of the National Academy of Sciences, 117, 11975-11980, https://doi.org/10.1073/pnas.1920849117

Lee CY, Tippett M, Sobel A, Camargo SJ (2016) Rapid intensification and the bimodal distribution of tropical cyclone intensity. Nature Communications, 7, 10625, https://doi.org/10.1038/ncomms 10625

Mastrandrea MD et al (2010) Guidance Note for Lead Authors of the IPCC Fifth Assessment Report on Consistent Treatment of Uncertainties. Intergovernmental Panel on Climate Change (IPCC). Available online at http://www.ipcc.ch

Mason M, Haynes K (2010) Adaptation lessons from Cyclone Tracy, National Climate Change Adaptation Research Facility, Gold Coast, 82 pp.

McGregor JL, Dix MR (2008). An updated description of the Conformal-Cubic Atmospheric Model. High Resolution Numerical Modelling of the Atmosphere and Ocean. K. Hamilton and W. Ohfuchi, Springer: 5176, https://doi.org/10.1007/978-0-387-49791-4_4

Su CH, Eizenberg N, Steinle P, Jakob D, Fox-Hughes P, White CJ, Rennie S, Franklin C, Dharssi I, Zhu H (2019) BARRA v1. 0: the bureau of meteorology atmospheric high-resolution regional reanalysis for Australia. Geoscientific Model Development, 12, 2049-2068.

Su CH, Ye H, Dowdy AJ, Pepler A, Stassen C, Brown A, Tucker SO, Steinle PJ (2021) Towards ACCESS-based regional climate projections for Australia, submitted.

Van Vuuren DP et al (2011) The representative concentration pathways: an overview. Climatic Change, 109, 5-31, https://doi.org/10.1007/s10584-011-0148-z

Velden C, Harper B, Wells F et al (2006) The Dvorak Tropical Cyclone Intensity Estimation Technique: A SatelliteBased Method That Has Endured For Over 30 Years. Bulletin of the American Meteorological Society, 87, $1195-1214$.

Wang C, Wang X, Khoo YB (2013) Extreme wind gust hazard in Australia and its sensitivity to climate change. Natural Hazards, 67, 549-567, https://doi.org/10.1007/s11069-013-0582-5 